\title{
Practice-oriented training of prospective teachers-speech therapists to work with stuttering preschoolers
}

\author{
N.V. Serebryakova ${ }^{1 *}$, and G.R. Shashkina ${ }^{2}$ \\ ${ }^{1}$ Moscow City University, Moscow, Russia \\ ${ }^{2}$ Moscow City University, Moscow, Russia
}

\begin{abstract}
The article focuses on the matters of studying the diagnostic competencies of prospective speech therapists, their readiness to apply the knowledge acquired in the process of corrective work with stuttering children, as well as the arrangement of the teaching internships for students. The necessity to develop these competencies of prospective speech therapists has to do with the formation of their professional competencies required by the Federal State Educational Standard of Higher Education.
\end{abstract}

\section{A problem statement}

At the current phase the professional culture of a teacher is based on the contents of pedagogical training, which centers on shaping both pedagogical and diagnostic competencies [1,2]. The basic professional competencies stated in the Federal State Educational Standard enable the speech therapist to identify speech impediments in preschool children. Mastering diagnostic competencies is vital in the study of children with speech impediments, in particular, stuttering preschoolers [3].

Stutter is considered to be one of the difficult speech impediments, it is problematic in terms of correction, more often we can only speak about an alleviation of its gravity. The effectiveness of speech therapist's work and the further social adjustment of the child in a preschool educational institution depend on the precision of the speech therapist's speech conclusion, drawing up a plan of corrective actions. The most challenging task is presented by the study of the speech activity of children with stutter aggravated with general speech underdevelopment or mental retardation [4].

Teaching and bringing up children of early and early preschool age (from 2 to 4 ) is one of the most crucial tasks at the current stage of development of preschool education all over the world. A review of the policy in the area of early preschool education, specifics of documentation and communication, the quality of childcare, the study and comparison of aspects of the quality of the upbringing process in European preschool education makes it possible to consider the upbringing of young children one of the top priorities of modern education [5-8]. This trend is also characteristic of specialized preschool education in

\footnotetext{
*Corresponding author: ipcs-profped@yandex.ru
} 
Russia. Consequently diagnostic competencies of identifying stutter in young children have gained particular importance.

Familiarizing students with the basics of diagnostics and correction of stutter commences with mastering the subject of "Speech therapy (tempo-rhythmic speech impediments)". The development of diagnostic competencies of prospective speech therapists is achieved through studying the subject of "Psychological and pedagogical diagnostics of children with speech impediments" and is enhanced during pedagogical internships in various educational institutions [9].

When studying tempo-rhythmic impediments, students are taught about the historical aspect of the development of the theory of stutter, the variety of acoustic characteristics of speech, the psychophysiological mechanism of the formation of smooth and convulsive speech, a comparative analysis of domestic and foreign schools of stutter [10-13].

Theoretical training dwells on such aspects as the etiology and symptoms of stutter, a comparative analysis of the clinical forms of stutter. A special emphasis is made on the psychological and pedagogical characteristics of preschoolers with stutter, since a lot of upcoming speech therapists are going to work in preschool educational institutions. Technologies of speech therapy examination of preschoolers with stutter comprise the principles and methods of examining the speech activity of preschoolers with stutter, the study of motor and speech development in young children. Students watch video presentations of speech therapy examination of preschoolers with stutter, analyze symptoms of the impediments, afterwards they are to formulate a speech therapy conclusion and proceed with selecting appropriate speech therapy technologies to aid.

A lot of attention is paid to the technologies of teaching preschoolers with stutter in the inclusive education environment [14]. Methods of logopsychotherapy and musical rhythmics have proved effective in correcting stutter. For young children, Logorhythmics classes simultaneously focus on development of general speech competence of young children [15].

Psychological and pedagogical diagnostics familiarises students with the basics of psychological testing, students explore methods for studying higher mental functions, the procedure of conducting an examination and analyzing the data results. Covering such topics as "Modern technologies of a neuropsychological approach to the study of children's developmental deficiencies" and "The specifics of the structure of the communicative potential of personality of preschoolers experiencing difficulties with communication and speech development", shapes interdisciplinary connections and broadens upcoming teachers - speech therapists' horizons. [16, 17].

\subsection{The objective of the work}

To study the level of development of upcoming speech therapists' diagnostic competencies, we've held an experimental study among juniors and seniors of the Department of Speech Therapy of the Institute of Specialized Education and Psychology of the Moscow City Pedagogical University. The research involved 128 full-time and part-time students, 85 of them did full time, and 43 half-time respectively. The study had two stages. At the first stage, we conducted a survey on the main issues of psychological and pedagogical diagnostics. The second stage was centered on the analysis of a video film about the diagnosis of a stuttering child in a preschool educational institution.

The questions of the questionnaire involved an assessment of the theoretical foundations, tasks, diagnostic methods, a comparative analysis of diagnostic research techniques (10 questions), the difficulties of differential diagnostics in the selection of children to specialized educational institutions (6), their attitude to inclusive education (6) and methods of diagnosing early age children's motor skills and speech (8). The inquiry 
was conducted in their practical classes, the half-time students worked in a distance mode, whereas the full-time students were in their classrooms. The questionnaire questions were read out 3 times, it took the students 2-3 minutes to answer a question in writing. The fulltime students required an hour and a half to do 30 questions, while it took the half-time students an hour.

At the second stage, the students were asked to watch a video of the examination of a stuttering child's motor and speech functions, they answered the questions, described the results of the tasks performed by the children in the process of diagnostics. In conclusion, the students determined the child's speech status.

In the video, on examining motor functions, the speech therapist assessed all the aspects of the motor sphere of a stuttering child: articulatory motor skills, motor skills of the child's wrists and fingers, mimic motor skills, general voluntary motor skills and a sense of rhythm. To assess the quality of the child's movements, the students were asked to assess the possibility and correctness of their performance on a three-point scale. Where 2 points was the highest result (the child did everything correctly on his own, without the help of an adult, the first time), 1 point - the child completed the test task 2 times, inaccurately, with minor errors, with the help of an adult, 0 points - could not perform or performed 3 times with the help of an adult.

On examining the lexical and grammatical aspect of speech, the speech therapist asked a five-year-old child to compose a coherent story based on a series of plot pictures, to answer questions about them, the speech therapist asked the child to remove the odd one from 4 object pictures and explain their choice, name items from 1 to 5 . On examining the phonetic-phonemic aspect of speech the speech therapist asked to repeat the words of a complex syllabic structure, clap their hands if there was a sound " $\mathrm{A}$ " in the word, repeat a tongue twister after the speech therapist, and say a simple phrase with the speech therapist.

While watching the video, the students kept a diary, in which they wrote down the child's successes and mistakes assessing the gravity of cramps during stuttering, the type and location of cramps, the presence of neurotic manifestations, logophobias, the manifestation ofvegetative reactions, the quality of phonation breathing, the speech tempo and the expressiveness of intonation. The students were to formulate a speech therapy conclusion and determine the directions of work taking into account the results of the analysis. The video recording of the study of the child's motor functions lasted 15 minutes, the one of their speech activity - 25 minutes. The students were given 15 minutes to analyze and summarize the results.

\section{Materials and the results of the research}

The results of the questionnaire proved full-time students to be more successful with the questionnaire than with the analysis of the video. Whereas the half-time students coped better with the analysis of the video film as well as formulation of a speech therapy conclusion. It could be explained by the fact that half-time students are already working in preschool and school educational organizations as child minders of a preschool educational organization (ECE) or as elementary school teachers. They enter the university having graduated from secondary specialized education institutions (teacher training college). Meanwhile full-time students enter the institute on the basis of their USE scores after finishing high school. Though they do have great potential for a more thorough study of the theoretical foundations of specialized education. 
Table 1. Analysis of the study results of the full-time and half-time students' questionnaires in percentage points.

\begin{tabular}{|l|l|l|l|l|}
\hline Units of the questionnaire & \multicolumn{3}{|l|}{ Full-time students (85-100\%) } & $\begin{array}{l}\text { Half-time } \\
\text { 100\%) }\end{array}$ \\
\cline { 2 - 5 } & High level & Mid level & High level & Mid level \\
\hline $\begin{array}{l}\text { Theoretical foundations of } \\
\text { psychological and pedagogical } \\
\text { diagnostics }\end{array}$ & 80.00 & 20.00 & 55.81 & 44.19 \\
\hline $\begin{array}{l}\text { Differential diagnostics applied } \\
\text { selecting children for } \\
\text { specialized } \\
\text { institutions educational }\end{array}$ & 34.11 & 65.88 & 60.46 & 39.54 \\
\hline $\begin{array}{l}\text { Attitude towards inclusive } \\
\text { education of differently abled } \\
\text { children }\end{array}$ & 91.76 & 8.23 & 88.37 & 11.62 \\
\hline $\begin{array}{l}\text { Diagnostic techniques of young } \\
\text { children's motor skills and } \\
\text { speech }\end{array}$ & 94.47 & 3.53 & 95.35 & 4.65 \\
\hline
\end{tabular}

The analysis of the questionnaire proved that the questions concerning the theoretical foundations of psychological and pedagogical diagnostics (PPD) turned out to be more interesting and easier for full-time students. 68 full-time students (80\%) completely coped with the questions of the first theoretical block. 17 students $(20 \%)$ demonstrated slight inaccuracies in the analysis of methods and techniques of psychological and pedagogical diagnostics in terms of selecting children for specialized (corrective) institutions at the psychological. medical and pedagogical commission. The questions of describing the principles and tasks of PPD turned out to be more challenging for half-time students. 19 students $(44.19 \%)$ experienced significant difficulties. On the other hand. more than half of the students $(55.81 \%)$ coped with the questions related to PPA techniques.

The questions of differential diagnostics in the selection of children for specialized educational institutions turned out to be more challenging for full-time students. 56 fulltime students $(65.88 \%)$ coped with the questionnaire on the mid level. They found it hard to analyze the structure of the defect in children with various developmental deviations. 26 part-time students $(60.46 \%)$ showed a high level of knowledge on this block of questions.

The block of questions assessing attitudes towards inclusive education was successful for many students participating in the study. Almost all students realize the importance of including differently abled children in common educational space. Analyzing the questionnaires of students. one can notice that together with inclusive education. the students do support state structures of a specialized (corrective) profile for children with severe. concomitant. combined developmental deviations. The percentage of successful answers to the questions of this block does not differ dramatically among students of fulltime and half-time modes of attendance. $91.76 \%$ of day-time students versus $88.37 \%$ of half-time students.

The block of questions of studying the methods of diagnostics of motor skills and speech of young children demonstrated some significant progress in mastering a number of disciplines related to the early motor and speech development of children. All the students fully coped with the questions of this block. except for 5 students of both modes of attendance. This confirms that the teachers of the Department of Speech Therapy pay special attention to the diagnostics and correction of developmental deviations in young children [18].

The results of the analysis of the video film demonstrating the examination of a stuttering child proved that the full-time students have higher results when it comes to the organization of speech therapy examination of stuttering children in comparison with the 
half-time students. It may have to do with the fact that half-time students work in educational organizations for children with ordinary psychophysical development. where stuttering children are rare. On the other hand. an analysis of the curricula for the study of this discipline demonstrates that full-time students are allocated much more time on mastering this discipline in the context of a classroom compared with the half-time students (full-time - 12 lecture hours. 26 practical ones; half-time - 12 lecture hours. 12 practical hours ) [19].

The analysis of the examination of the motor functions of a stuttering child showed that $81.4 \%$ of half-time students coped with handling the topic of organizing the examination of the motor and speech functions of stuttering preschoolers. There were $69.41 \%$ of successful full-time students. Students demonstrated specific knowledge analyzing the qualitative specifics of the state of motor disorders in stuttering children.

The analysis of the examination of the lexical and grammatical aspect of a stuttering child's speech was somewhat lower in terms of quality than the examination of motor functions. $65.12 \%$ of half-time students fully succeeded in analysing the state of coherent speech. active vocabulary and inflectional skills of a stuttering child. 53 Full-time students $(62.35 \%)$ also successfully coped with the analysis. The differences between the two groups in this diagnostic section are insignificant.

Table 2. Analysis of the results of watching a video film by full-time and half-time students in percentage points $\%$.

\begin{tabular}{|l|l|l|l|l|}
\hline \multirow{2}{*}{ Study units } & \multicolumn{3}{|l|}{ Full-time students (85-100\%) } & $\begin{array}{l}\text { Half-time students (43- } \\
\mathbf{1 0 0 \% )}\end{array}$ \\
\cline { 2 - 5 } & High level & Mid level & High level & Mid level \\
\hline $\begin{array}{l}\text { Analysis of stuttering child's } \\
\text { motor function examination }\end{array}$ & 69.41 & 30.59 & 81.40 & 18.60 \\
\hline $\begin{array}{l}\text { Analysis of examination of } \\
\text { lexico-grammatical aspect of } \\
\text { speech }\end{array}$ & 62.35 & 37.64 & 65.12 & 34.88 \\
\hline $\begin{array}{l}\text { Analysis of the speech in terms } \\
\text { of phonetics and phonology }\end{array}$ & 61.18 & 38.82 & 74.42 & 25.58 \\
\hline $\begin{array}{l}\text { Analysis of the examined tempo } \\
\text { and rhythm of the speech }\end{array}$ & 80.00 & 20.00 & 90.70 & 9.30 \\
\hline $\begin{array}{l}\text { Formulation of speech } \\
\text { therapist's conclusion }\end{array}$ & 84.70 & 15.30 & 60.47 & 39.53 \\
\hline
\end{tabular}

Analyzing the examination of a preschooler's phonetic-phonemic side of speech. the students handled the analysis well. however they found it difficult to analyze the assessment of the quality of the child's distorted sounds (replacement. distortion or confusion). 52 students $(61.18 \%)$ were successful. Half-time students demonstrated slightly better results than full-time students. $74.42 \%$ succeeded in analysing the state of pronunciation and perception of phonemes.

Analyzing the examination of a stuttering child's tempo and rhythm of speech. the success rates were the best in students of both forms of education. $80 \%$ of full-time students versus $90.7 \%$ of half-time students. An analysis of the gravity of stutter. type and localization of cramps is the basic knowledge of the theory of stutter. which may have influenced the success of this task.

The last. but not least is the formulation of a speech therapy conclusion resulted out of analysing the video. The full-time students were more successful at accomplishing it $(84.7 \%)$ than the half-time ones $(60.47 \%)$. This is the result of them having a large number of practice-oriented classes included in the curriculum of bachelors of the full-time mode. 
The results of the conducted study show that full-time and halftime students master the professional competencies of selecting diagnostic tools and methods meeting the objectives of the study and the capabilities of a particular child (PC-1.2) while studying the subjects of the profile "Speech therapy". They are aware of the technologies of conducting diagnostic examination of children with developmental deviations. including the interpretation of the results. they are able to plan the directions of corrective and developmental work based on the results of monitoring. taking into account the individual characteristics of the development of each child.

It must be pointed out that the issue of differential diagnostics while selecting children for specialized educational institutions. the matters of studying methods and the techniques of conducting speech therapy examination of stuttering children with combined stutter. as well as issues of organizing inclusive education of stuttering preschoolers in the comprehensive educational environment remain pretty controversial.

To cope with these tasks. in terms of solving the problem of updating the theoretical knowledge of students. in accordance with the requirements of the State Federal Educational Standard. professors and associate professors of the Moscow City Pedagogical University have worked out curriculums $t$ providing interdisciplinary connections in accordance with the bachelor's curriculum [20. 21]. The key subjects of the Humanities module are such classes as "Thinking and Writing". "Great Books". "Cultural Codes". In this module "Socio-cultural practice" takes place for freshmen; students visit city libraries. analyze literature on the matters of intercultural communication.

The psychological and pedagogical module comprises such subjects as "Pedagogy". "Psychology". "Age pedagogy and psychology". The "Basic and additional education development" class introduces educational organizations. with basic and additional educational programs to students. The discipline of "Technologies of professional communication and the acting skills of a teacher" is meant to shape students' ability to communicate easily with children with certain developmental features. Such subjects as "Organization. control and assessment of educational activities". "Information and telecommunication technologies in education". "Moscow education system" enables students to be proficient computer users. gives good understanding of the application of information technology in the system of Moscow school education (Moscow Electronic School).

To implement a practice-oriented approach in the formation of diagnostic competencies. this module covers three types of practice: introductory. social and psychological and pedagogical. Juniors do their internships in psychology and pedagogy going to different educational organizations. observing the work of speech therapists. conducting psychological and pedagogical diagnostics of children. holding trial group and individual classes with children with speech impediments. learning to draw up paperwork appropriately.

The basic part of the professional cycle includes the discipline of "Patterns of neuropsychic and speech development". where students familiarise themselves with the specifics of preschool children development. In the process of speech diagnostics. the speech therapist applies one of the vital principles of the analysis of speech disorders. namely. the ontogenetic principle. Awareness of the patterns of speech development enables a speech therapist to identify a speech disorder. and in some cases. to determine a peculiar way of a child's speech development. The basic part of the cycle comprises specialized pedagogy and psychology. the disciplines of biomedical foundations of defectology.

The discipline of "Psychological and pedagogical diagnostics of children with speech disorders" belongs to the disciplines of the elective part and is studied by juniors before their teaching internship. The elective block includes 20 disciplines. 12 of which have to do 
with people with speech impediments (profile "Speech therapist"). The formation of diagnostic competencies is enhanced by the disciplines of this profile. The study of the basics of diagnostics and correction of speech disorders is based on conventional and innovative aspects [22]. parallels with foreign technologies are drawn [23].

The other 8 disciplines shape the pedagogical competencies of teaching and bringing up differently abled people. complementing and clarifying the professional competences of a speech therapist in an inclusive education environment; teaching and supporting young children; assisting parents and counseling families. The discipline of "Specialized (corrective) and inclusive education of children with various developmental disorders" draws parallels between two systems of providing speech therapy assistance: in the context of specialized and inclusive education systems. Students explore the challenges of upbringing and development of young children within the framework of the course of "The System of early comprehensive care for disabled children." The discipline of "Pedagogical systems of teaching and upbringing of children with speech impediments" introduces students to various schools and approaches to teaching children with speech development challenges in Russia and abroad. "Methodology for the development of preschoolers' speech" is interconnected with the discipline of "Preparing children with speech impediments for school." The discipline of "Psychological. pedagogical. medical and social support to children with disabilities in institutions of different departments" introduces students to the organization of speech therapy aid in educational. healthcare and child protection institutions.

Some elective courses are dedicated to the differential diagnostics of disorders: "Modern approaches to comprehensive speech therapy examination". "Diagnostics and correction of speech impediments in adolescents and adults".

Such subjects as "Comprehensive rehabilitation of children with musculoskeletal disorders". "Art pedagogy and art therapy in the social adaptation of children with developmental problems". "Corrective and pedagogical work with children with severe speech impediments" shape the competencies necessary to develop training programs for people with disabilities.

Professors of the Department of Speech Therapy at the Institute of Specialized Education and Psychology of the Moscow City Pedagogical University have developed elective courses enabling prospective professionals to prevent deviations in the development of speech in young children. to ensure social adaptation and development of speech in young children. These disciplines include "Social development of infants and young children". "Early stimulation of psychomotor and speech development of children with disabilities" and "Technologies for developing an individual educational route for differently abled children in the first years of their lives". The contents of these disciplines is also relevant for the development of speech in young children without development issues.

Professors combining university teaching with practicing in modern schools working according to the system of inclusive education have developed programs for mastering disciplines in line with the Federal State Educational Standard. The elective classes "Teaching first graders with speech impediments to read within the framework of the FSES implementation" and "Literacy lessons for first graders with speech disorders within the framework of the FSES implementation" contain a comparative analysis of the methodology for teaching children to read and literacy currently used. as well as unconventional methods of teaching reading.

Each curriculum of any subject comprises:

- the goal and objectives of the subject. the place of the subject in the structure of the main educational curriculum; requirements for the results of mastering the discipline;

- the scope to cover and types of educational activities; 
- the discipline contents (the contents of sections and topics

- interdisciplinary links with previous supporting disciplines as well as links with subsequent disciplines;

- themes of tests and topics of graduation works (or projects);

- methodological and informational support (the key and additional literature. databases. reference and search engines);

- material support and methodological guidelines to master the discipline.

The development and implementation of video training simulators enabling the formation of basic skills in the diagnostic analysis of complex combined speech impediments. are top priorities for the Department of Speech Therapy. Educational video simulators for the main disciplines of the "Speech therapy" major cover videos containing diagnostic studies of the speech activity of children and adults. recorded by speech therapists in various institutions.

Thus studying the discipline of "Speech therapy (Dysarthria)". students master the technology of differential diagnostics of complex forms of dyslalia and mild dysarthria. Studying phonetic-phonemic disorders and general speech underdevelopment is meant to develop students' skills for differentiating these speech disorders. The video presented on this subject contains more than 20 fragments of the study of the speech activity of preschoolers according to the methodology of Professor V.I. Yashina (method of express diagnostics). Resorting to this technique. all components of the speech of preschoolers are studied in a short time (up to 20 minutes). Each speech component is represented with three indicative tasks. Comparing children's answers to these questions. students master the basic skill. namely. the ability to distinguish between children with phonetic and phonemic speech impediments and general speech underdevelopment.

Students studying the discipline of "Speech therapy (Aphasia)" are required to study the protocols of speech questioning of patients after a stroke or traumatic aphasia. The protocols are equipped with a test that assesses speaking. reading. writing. counting. gnosis and praxis of patients with aphasia. Analyzing the examination protocols. students develop the skill of differential diagnostics of various local and mixed forms of aphasia. Exploring the subject of "Speech therapy (Dysgraphia)". students examine samples of written works of students with writing disorders learning to identify dysgraphic and dysorthographic errors. the form and degree of dysgraphia. and study teaching methods for various forms of dysgraphia.

Workshops in the disciplines of the variable part of the curriculum are held in institutions of different types. Students discover the contents of speech therapists' work in kindergartens and schools. centers for the development and support of differently abled children. in speech therapy rooms of children's clinics.

- Creating conducive environment to structure the theoretical knowledge acquired studying the classes of "Speech therapy". "Psychological and pedagogical diagnostics". "Psycholinguistics". "Logopsychology" and others;

- organization of practical classes for students aimed at mastering the organizational. methodological and technological components of education;

- shaping reflexive activity of prospective professionals targeted at analyzing the factors of the pedagogical process and the results of handling educational challenges;

- assisting students in mastering the gnostic actions of analysis. assessment. control and correction in the development and conduct of individual and frontal speech therapy classes;

- providing conditions for teaching. training and bringing up children with speech impediments. as well as diagnostics. correction and compensation of defects in their speech development;

- attracting students to all events arranged by a speech therapist;

- attracting students to complex work in specialized educational institutions; 
- familiarising students with the specifics of speech therapists' work in groups and classes for children with phonetic-phonemic and general speech underdevelopment. stutter. dyslexia and dysgraphia.

Senior year. students take advantage of continuous practice (internship) in educational institutions of Moscow. Being supervised by a teacher of the department and a speech therapist of the institution. future professionals study the speech activity of children of different ages. analyzing the examination data. drawing the conclusions of their training in the final qualification work.

It is possible to take advantage of two options to create and presentat one's final assessment work. namely. research and a project. There is a great variety of topics to choose from for the projects. it meets the requirements of modern specialized pedagogy. it is relevant and supports the concept of inclusive education.

To gain a better understanding of integration issues and shaping a positive attitude of teachers - speech therapists towards children with developmental deviations. teachers of the Department of Speech Therapy. together with students. attend open days in secondary schools. where special needs children go together with their peers (GBOU SCS No. 518 and No. 587).

The faculty of the Department of Speech Therapy of the Moscow City Pedagogical University conduct scientific and practical seminars on the topic "Experience of integration into educational institutions of Moscow" in its branch in the city of Zelenograd. They will familiarise students with a model of psychological and pedagogical support for young children with developmental deviations. with the work of specialists from the State Educational Institution No. 2022 of the Central Administrative District of Moscow. where children with complex developmental disabilities study. Particular attention is paid to volunteer work of students in public organizations. for example. in the public non-profit organization "Perspective".

\section{Conclusions}

The fundamental professional competencies formulated in the Federal State Educational Standard of a specialized teacher (44.03.03-Specialized (defectological) education-Speech therapy) enable the speech therapist to select diagnostic tools and methods meeting the research goals and capabilities of a particular child. Mastering diagnostic competencies is especially crucial when studying children with speech impediments. including stuttering preschoolers.

To study the level of development of diagnostic competencies of upcoming speech therapists. we have conducted research among 3rd and 4th year students of the Department of Speech Therapy of the Institute of Specialized Education and Psychology of the Moscow City Pedagogical University. The results of the research clearly demonstrate that once having studied the subjects required for the major of Speech Therapy. full-time students and part-time ones have a good command of the technology of conducting a diagnostic examination of children with developmental deviations. including the interpretation of the results. they are good at planning and defining the tasks of corrective and developmental work based on the results of monitoring. taking into consideration individual developmental specifics of each child.

Although differential diagnostics in the process of selecting children for specialized educational institutions. the study of methods and techniques of conducting speech therapy examination of stuttering children with combined stutter. issues of organizing inclusive education of stuttering preschoolers in the comprehensive educational environment are still a matter of debate. 
To handle these tasks. to meet the necessity of maintaining the theoretical knowledge of students up to date. in accordance with the requirements of the State Federal Educational Standard. professors and associate professors of the Department of Speech Therapy of the Institute of Specialized Education and Psychology of the Moscow City Pedagogical University have developed a curriculum. practice-oriented lectures. video simulators. and elective training classes for students. The system of arrangement of teaching internships for students of the Speech Therapy Department is aimed at developing the skills to work in an educational organization. observing the work of a speech therapist. conducting psychological and pedagogical diagnostics of children. trial group and individual lessons with children with speech impediments. as well as correctly filing paperwork.

Modern technologies of training prospective speech therapists to work with children who have complex and combined speech impediments. come from merging the experience and achievements of foreign specialized pedagogy. traditions with innovations of the national school of specialized training. with the legal framework of the organization and management of specialized education.

\section{References}

1. K.A. Barannikov, S.N. Vachkova, M.Yu. Demidova, I.M. Remorenko, O.A. Reshetnikova, Education Bulletin. About the regulation of the contents of education at the current stage of the restructuring of the education system in the Russian Federation, 14, 69-80 (2016)

2. I.M. Remorenko. I.B. Shiyan. O.A. Shiyan. T.G. Shmis. T.N. Levan. Ya.Ya. Kozmina. E.V. Sivak. The Key issues of the implementation of the Federal State Educational Standard of Preschool Education based on the results of a study taking advantage of "scales for a comprehensive assessment of the education quality in preschool educational institutions", Modern preschool education, 2 (74), 16-31 (2017)

3. Yu.O. Filatova Innovative aspects of speech therapists' training in the XXI century. The Teacher of the XXI century. 3 20-26 (2008)

4. Corrective rhythmics for preschoolers with mental retardation issues. Education and upbringing of children with developmental disorders, 3, 48-53 (2018)

5. Y. Anders. W.S. Barnett. A. Engel. M. Taguma. Early childhood education and care policy review (Norway - OECD Publishing, 2015)

A. Emilson, I. Pramling Samuelsson, Documentation and communication in Swedish preschools Early Years, 34, 2 175-187, access mode: http://dx.doi. org/. DOI: 10.1080/09575146.2014.880664 (2014)

6. H.J. Vermeer, M.H. van I. Jzendoorn, R.A. Carcamo, L.J. Harrison, Quality of Child Care Using the Environment Rating Scales: A Meta-Analysis of International Studies, International Journal of Early Childhood, 48 (1), 33-60 (2016)

7. E. Zachopoulou Grammatikopoulos, V. Gregoriadis, A. Gamelas, A. Leal, T, Pessanha, M. Barros, S. Liukkonen, J. Loizou, E. Henriksen, C. Sanders, L. Olesen, L. Ciolan, Comparing aspects of the process quality in six European early childhood educational settings, 6th International Conference of Education. Research and Innovation. Conference abstracts (Seville, Spain, 2013)

8. D. Plyuta-Voitsekhovska, Yu.O. Filatova, The Modern trends in speech therapy diagnostics and correction are the theme of the international conference on speech therapy. Defectology, 1, 88-91 (2016) 
9. A.A. Almazova, G.V. Babina, Yu.O. Filatova, A feature article on the scientific school of Professor L.I. Belyakova. Education and upbringing of children with developmental issues, 1, 43-48 (2019)

10. W. Hulstijin. P. Van Lieshout. H. Peters On the measurement of coordination, Speech Motor Control and Stuttering 211-230 (ed. by H. Peters, et al., Elsiver Science Publishers, 1991)

11. D. Ward \& K. Scaler Scott (Eds.) Cluttering: A Handbook of Research. Intervention and Education; Hove and NY., 307 (2011)

12. E.G. Conture, Stuttering: Its Nature. Diagnosis. and Treatment (Needham Heights, MA 2001)

13. E.T. Loginova. Modern challenges of specialists' training in the field of special needs education, Bulletin of the Cherepovets State University, 1 (28), 12-19 (2011)

14. N.V. Serebryakova, G.R. Shashkina, Development of the lexical and grammatical system in differently abled young children in the context of inclusive education. Challenges of contemporary training of teachers, Collection of scientific works: Yalta: RIO GPA, 67 (4), 341-345 (2020)

15. T.N. Volkovskaya, Neuropsychological approach to the study of developmental shortcomings of children with early organic lesions of the central nervous system. Specialized psychology, 3, 32 (2010)

16. T.N. Volkovskaya, I.A. Kutkova, The specifics of the structure of the communicative potential of the personality of preschoolers with challenges in communicative-speech development. Modern scientist, 2, 62-65 (2020)

17. O.G. Prikhodko. O.V. Yugova, Psychological and pedagogical diagnostics of developmental disorders in children of the first years of life, Specialized education, 2 (42), 85-93 (2016)

18. The Curriculum for students of the Speech Therapy Department 2019-2020 ISOiP GAOU VO MGPU, access mode: https://d.mgpu.ru/plan/update?id=862

I. Froumin, I. Remorenko, from the "best-in-the world" soviet school to a modern globally competitive school system. In the compendium: Audacious Education Purposes. How Governments Transform the Goals of Education Systems, Collected articles 233-250 (Cambridge, 2020)

19. I.M. Remorenko, T.F. Dubova, M.L. Churaeva, N.I. Maksimov, E.V. Karavaeva, E.N. Kovtun, S.V. Korshunov, V.L. Petrov, N.M. Rozina, E.B Belov, B.A. Sazonov, From the federal state educational standards to university programs. Higher education in Russia, 8-9, 3-11 (2010)

20. Yu.O. Filatova, V.S. Demekhina, Special Pedagogy and Psychology: Traditions and Innovations (about the All-Russian Scientific Conference of Young Scientists at Moscow State Pedagogical University), Education and upbringing of children with developmental disorders, 5, 33-38 (2019)

21. St. K.O. Louis, Y. Filatova, M. Coşkun, S. Topbaş, S. Özdemr, D. Georgieva, E. Mccaffrey, R.D. George, Identification of cluttering and stuttering by the public in four countries, International Journal of Speech-Language Pathology, 12 (6), 508-519 (2010) 